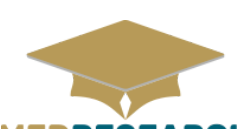

MEDRESEARCH

www.medresearch.in

\title{
A study on knowledge about hand hygiene among medical, dental and nursing students in Bangalore, Karnataka
}

\author{
Gore C. A. ${ }^{1}{ }^{*}$, Bindu M. ${ }^{2}$, Saxena L. ${ }^{3}$ \\ DOI: https://doi.org/10.17511/ijphr.2018.i3.02 \\ 1* Chaitali Ashutosh Gore, Associate Professor, Department of Community Medicine, Vydehi Institute of Medical Sciences \& Research \\ Centre, Bangalore, Karnataka, India. \\ 2 Bindu M, Undergraduate Medical Student, Vydehi Institute of Medical Sciences \& Research Centre, Bangalore, Karnataka, India. \\ 3 Lubdha Saxena, Undergraduate Medical Student, Vydehi Institute of Medical Sciences \& Research Centre, Bangalore, Karnataka, India.
}

Introduction: Hands are the main pathway of germ transmission during health care. Health care associated infections are the major concern when it comes to patient safety. Lack of hand hygiene leads to a serious problem in health care services as they may cause prolonged hospital stay. This study aims at assessing and comparing the knowledge regarding hand hygiene among undergraduate medical, dental and nursing students. Method: A cross-sectional, questionnairebased study was undertaken among 150 undergraduate medical, dental and nursing students studying in a Tertiary care teaching Institute in Bangalore, Karnataka. Data collection was done using World Health Organization hand hygiene questionnaire for health care workers. Analysis was done using SPSS version 21. Results: A total of 150 students participated in the study. Of these 48 were medical, 50 were dental and 52 were nursing students. Only 87 out of 150 (58\%) students had received training in hand hygiene in past 3 yrs. The medical and nursing students had very poor knowledge that unclean hands of health care workers can transmit harmful germs to patients, whereas dental students had better knowledge about the same and the difference was statistically significant. Knowledge regarding washing of hands after exposure to blood was better among nursing students than medical and dental students. Conclusion: The knowledge about hand hygiene was not satisfactory among the students. Hand hygiene training can be made mandatory for medical, dental and nursing students as they handle patients.

Keywords: Dental, Hand hygiene, Health care, Medical, Nursing, Students, Introduction

Corresponding Author

Chaitali Ashutosh Gore, Associate Professor, Department of Community Medicine, Vydehi Institute of Medical Sciences \& Research Centre, Bangalore, Karnataka, India.

Email: drchaitaligore@gmail.com

\section{How to Cite this Article}

Gore CA, Bindu M, Saxena L. A study on knowledge about hand hygiene among medical, dental and nursing students in Bangalore, Karnataka. Public Health Rev Int J Public Health Res. 2018;5(3):111116.

\section{Available From}

https://publichealth.medresearch.in/index.php/ijphr/ article/view/91
To Browse

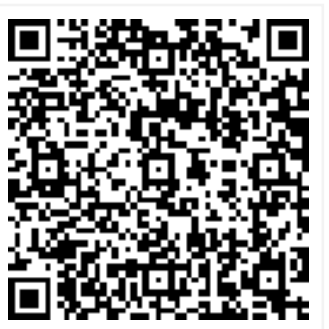

Manuscript Received 2018-08-10

Conflict of Interest No

(C) 2018 by Chaitali Ashutosh Society. This is an Open

Gore, Bindu M, Lubdha Saxena and Put pen Access article licensed under a Creative Commons Attribution 4.0 International License https://creativecommons.org/licenses/by/4.0/ unported [CC BY 4.0].

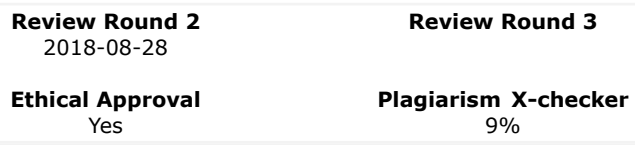

Note 


\section{Introduction}

Thousands of people die every day around the world from infections acquired while receiving health care. Hands are the main pathway of germ transmission during health care. Hand hygiene is therefore an important measure to avoid the transmission of harmful germs and prevent health care associated infections [1].

Hand hygiene is of paramount importance for prevention of health care associated infections and spread of antimicrobial resistance. There is a need to explore the concept of hand hygiene among cross disciplinary under-graduate health care students. Health care associated infections are a major concern when it comes to patient safety; hand hygiene remains the primary measure to reduce health care associated infections and the spread of antimicrobial resistance across all settings from advanced health care system to local dispensaries in developing countries [2].

Any health care worker, care giver or person involved in direct or indirect patient care needs to be concerned about hand hygiene and should be able to perform it correctly and at right time. Effective hand hygiene is the simplest proven method to reduce the prevalence of health care associated infections.

Unfortunately, the prevalence of these infections continues to rise and it is estimated that annually about hundreds of millions of patients suffer from health care associated infections over the world. Therefore, infection control is necessary to reduce the high levels of healthcare associated infections and the importance of hand hygiene in the control of infections cannot be over emphasized $[3,4]$.

Lack of hand hygiene leads to a serious problem in health care services as they may cause prolonged hospital stay, high mortality, longer term disability and excess health care cost. Most health care associated infections can be transmitted from patient to patient via the hands of health care workers due to poor hand hygiene. This is usual type of vehicle for transmission of health care associated infections [3].

The World Health Organization has issued guidelines for procedural hand washing in order to reduce the prevalence of hospital associated infections but a lack of knowledge among the health care workers is associated with poor compliance [1].
An alarming revelation was that compliance was found to be the worst before high risk procedures $[5,6]$. Despite evidence and expert opinion hand hygiene reduces the transmission of potential pathogens or antimicrobial resistant organisms, proper hand hygiene among health care workers are uncommon even after educational effort [7].

In India, there is very little data regarding awareness of the medical personnel including students of medical, dental and nursing about hand hygiene. Hence this study will be useful to understand the prerequisites for forming guidelines in this regard. This study aims at assessing and comparing the knowledge regarding hand hygiene among undergraduate medical, dental and nursing students.

\section{Materials and Methods}

Place of study: Tertiary care teaching Institute in Bangalore, Karnataka.

Type of Study: A cross-sectional, questionnairebased study.

Study period: January to May 2017

Sampling Methods: Simple Random Sampling was done. 50 undergraduate students were chosen from Medical, Dental and Nursing field.

Sample Collection: World Health Organization hand hygiene questionnaire for health care workers [1]

Inclusion Criteria: All the randomly selected participants who were willing to participate in the study were included

Statistical Methods: Data was analyzed using percentages and Chi-square test. Analysis was done using SPSS (Statistical Package for Social Sciences) version 21 software.

Approval was obtained from the ethical committee. Informed consent was obtained from the students before the study and they were explained about the purpose of the study. Confidentiality and anonymity of the information was assured.

\section{Results}

A total of 150 students participated in the study. Of these 48 were medical, 50 were dental and 52 were nursing students. Out of 150 , females were 88 $(58.7 \%)$ and males $62(41.3 \%)$. 
In the present study only 87 out of $150(58 \%)$ students had received training in hand hygiene in past 3 yrs. Amongst the medical students $70.8 \%$, dental $62 \%$ and nursing $42.3 \%$ received formal training in hand hygiene, this association was statistically significant as seen in Table I.

Table-I: Distribution of students according to
Hand hygiene training received in past 3 yrs

\begin{tabular}{|l|l|l|l|l|l|l|}
\hline \multirow{2}{*}{ Groups } & \multicolumn{6}{|c|}{ Formal training in hand hygiene in past 3 yrs } \\
\cline { 2 - 8 } & Yes & \multicolumn{3}{|c|}{ No } & Total \\
\cline { 2 - 7 } & Number & $\%$ & Number & $\%$ & Number & $\%$ \\
\hline Medical students & 34 & 70.8 & 14 & 29.2 & 48 & 100 \\
\hline Dental students & 31 & 62 & 19 & 38 & 50 & 100 \\
\hline Nursing students & 22 & 42.3 & 30 & 57.7 & 52 & 100 \\
\hline \multicolumn{7}{|c|}{ P value $<0.05$} \\
\hline
\end{tabular}

Table-II: Knowledge on hand hygiene among Medical, Dental and Nursing students.

\begin{tabular}{|c|c|c|c|c|c|}
\hline Sr No. & Questions & $\begin{array}{l}\text { Medical } \\
\mathrm{n}=48 \mathrm{~N} \\
(\%)\end{array}$ & \begin{tabular}{c|}
$\begin{array}{c}\text { Dental } \\
\mathrm{n}=50 \mathrm{~N} \\
(\%)\end{array}$ \\
\end{tabular} & $\begin{array}{l}\text { Nursing } \\
\mathrm{n}=52 \mathrm{~N} \\
(\%)\end{array}$ & $\begin{array}{l}\text { Significance S- } \\
\text { Significant NS-Not } \\
\text { significant }\end{array}$ \\
\hline 1. & $\begin{array}{l}\text { Which of the following is the main route of cross-transmission of potentially harmful } \\
\text { germs between patients in a health-care facility (Health-care workers' hands when } \\
\text { not clean) }\end{array}$ & $2(4)$ & $27(54)$ & $9(17)$ & $s$ \\
\hline 2. & $\begin{array}{l}\text { What is the most frequent source of germs responsible for health care-associated } \\
\text { infections (Germs already present on or within the patient) }\end{array}$ & $5(10)$ & $18(36)$ & $8(15)$ & $\mathrm{s}$ \\
\hline
\end{tabular}

The medical and nursing students had very poor knowledge that unclean hands of health care workers can transmit harmful germs to patients, whereas dental students had better knowledge about the same and the difference was statistically significant. as shown in Table II.

But when it came to actions for preventing
Transmission of germs to the patients, medical students had good knowledge as compared to dental and nursing students.

In case of actions to prevent transmission of infection to healthcare workers again medical students had better knowledge as compared to dental and nursing students as shown in Table 3.

Table-III: Knowledge on hand hygiene regarding prevention of transmission of germs to patients and health care workers.

\begin{tabular}{|c|c|c|c|c|c|}
\hline$\left|\begin{array}{c|}\text { Sr } \\
\text { No. }\end{array}\right|$ & Questions & $\begin{array}{l}\text { Medical } n=48 \\
\qquad(\%)\end{array}$ & $\begin{array}{l}\text { Dental } \mathbf{n = 5 0} \\
\qquad N(\%)\end{array}$ & $\begin{array}{c}\text { Nursing } \mathbf{n}=\mathbf{5 2} \\
\mathrm{N}(\%)\end{array}$ & $\begin{array}{c}\text { Significance S-Significant NS-Not } \\
\text { significant }\end{array}$ \\
\hline \multirow[t]{5}{*}{3.} & \multicolumn{5}{|c|}{ Which of the following hand hygiene actions prevents transmission of germs to the patient } \\
\hline & Before touching a patient (Yes) & $46(96)$ & $42(81)$ & $50(96)$ & $\mathrm{s}$ \\
\hline & Immediately after a risk of body fluid exposure (Yes) & $44(92)$ & $37(71)$ & $43(83)$ & NS \\
\hline & $\begin{array}{l}\text { After exposure to the immediate surroundings of a } \\
\text { patient (No) }\end{array}$ & $1(2)$ & $19(37)$ & $10(19)$ & $S$ \\
\hline & Immediately before a clean/aseptic procedure (Yes) & $46(96)$ & $41(79)$ & $40(78)$ & S \\
\hline \multirow[t]{4}{*}{4.} & \multicolumn{5}{|c|}{ Which of the following hand hygiene actions prevents transmission of germs to the health-care worker } \\
\hline & After touching a patient (Yes) & $44(92)$ & $42(84)$ & $35(67)$ & S \\
\hline & Immediately after a risk of body fluid exposure (Yes) & $47(98)$ & $39(78)$ & $49(94)$ & S \\
\hline & Immediately before a clean/aseptic procedure (No) & $3(6)$ & $20(40)$ & $16(31)$ & S \\
\hline
\end{tabular}

Regarding use of alcohol-based hand rub medical students had better knowledge regarding time required to kill most germs as compared to dental and nursing students and this difference was statistically significant. Knowledge regarding washing of hands after exposure to blood was better
Among nursing students than medical and dental students. All the students had good knowledge that if there is damaged skin or any artificial finger nail that can be source of colonization for germs as shown in Table 4. 
Table- IV: Knowledge on hand hygiene regarding use of hand rub and other situations.

\begin{tabular}{|c|c|c|c|c|c|}
\hline $\begin{array}{c}\text { Sr } \\
\text { No. }\end{array}$ & Questions & $\begin{array}{l}\text { Medical } n=48 \\
\qquad(\%)\end{array}$ & \begin{tabular}{|l} 
Dental $n=50$ \\
$N(\%)$
\end{tabular} & $\left|\begin{array}{c}\text { Nursing } n=52 \\
N(\%)\end{array}\right|$ & $\begin{array}{l}\text { Significance S-Significant NS- } \\
\text { Not significant }\end{array}$ \\
\hline \multirow[t]{6}{*}{5.} & \multicolumn{5}{|c|}{ Which of the following statements on alcohol-based hand rub and hand washing with soap and water are true } \\
\hline & Handrubbing is more rapid for hand cleansing than handwashing (True) & $21(48)$ & $28(56)$ & $14(27)$ & $S$ \\
\hline & Handrubbing causes skin dryness more than handwashing (False) & $11(23)$ & $22(44)$ & $12(27)$ & $S$ \\
\hline & Handrubbing is more effective against germs than handwashing (False) & $27(57)$ & $22(44)$ & $38(73)$ & s \\
\hline & $\begin{array}{l}\text { Handwashing and handrubbing are recommended to be performed in } \\
\text { sequence (False) }\end{array}$ & $9(19)$ & $15(30)$ & $26(50)$ & $S$ \\
\hline & $\begin{array}{l}\text { What is the minimal time needed for alcohol-based handrub to kill most } \\
\text { germs on your hands }(20 \mathrm{sec})\end{array}$ & $40(83)$ & $28(56)$ & $40(77)$ & $S$ \\
\hline \multirow[t]{6}{*}{6.} & \multicolumn{5}{|l|}{ Which type of hand hygiene method is required in the following situations } \\
\hline & Before palpation of the abdomen (rubbing) & $3(6)$ & $0(0)$ & $0(0)$ & S \\
\hline & Before giving an injection (rubbing) & $35(73)$ & $23(46)$ & $20(38)$ & s \\
\hline & After emptying a bedpan (washing) & $35(73)$ & $29(58)$ & $44(85)$ & $s$ \\
\hline & After making a patient's bed (rubbing) & $13(27)$ & $9(18)$ & $11(21)$ & NS \\
\hline & After visible exposure to blood (washing) & $37(77)$ & $32(64)$ & $42(81)$ & NS \\
\hline \multirow[t]{5}{*}{7.} & \multicolumn{5}{|c|}{ Which of the following should be avoided, as associated with increased likelihood of colonization of hands with harmful germs } \\
\hline & Wearing jewellery (Yes) & $17(13)$ & $27(54)$ & $13(25)$ & NS \\
\hline & Damaged skin (Yes) & $43(90)$ & $41(82)$ & $44(85)$ & NS \\
\hline & Artificial fingernails (Yes) & $44(92)$ & $37(74)$ & $26(50)$ & $S$ \\
\hline & Regular use of a hand cream (No) & $27(56)$ & $24(48)$ & $37(71)$ & NS \\
\hline
\end{tabular}

\section{Discussion}

In a study done in Iran $16.4 \%$ participants, in Ghana study $77.3 \%$ participants received training in hand hygiene, whereas in our study $58 \%$ participants were trained in hand hygiene $[8,9]$. Study done at Mumbai $14.2 \%$ medical, $14.8 \%$ dental and $95 \%$ nursing students received formal training in hand hygiene, in our study $70.8 \%$ medical, $62 \%$ dental and $42.3 \%$ nursing students received training in hand hygiene [10].

In the study done in Bhopal no significant difference in knowledge among the participants about the route of transmission of germs, but in our study dental students had better knowledge as compared to medical and nursing students and the difference was statistically significant [11]. The most frequent source of germs responsible for health careassociated infections are the germs already present on or within the patient. This answer was given correctly by $23.6 \%$ students in the Gulbarga study, whereas in our study only $10 \%$ students gave correct answer [12].

Medical and nursing students had better knowledge as compared to dental students regarding hand hygiene actions which prevent transmission of germs to the patient and this difference was statistically significant.
In the study done at Raichur there was no statistically significant difference in knowledge amongst medical and nursing students regarding the same [13]. The minimal time needed for alcohol-based handrub to kill most germs on your hands is 20 seconds, $83 \%$ medical and $77 \%$ nursing students had knowledge about this. In the Raichur study $38.3 \%$ medical and $27.8 \%$ nursing students had knowledge regarding the same [13].

In the study done in Iran $65.7 \%$ participants had moderate knowledge about hand hygiene [8]. In Bangladesh study, also the knowledge about hand hygiene was not sufficient among the students and emphasized on the importance of educating students about the same [14]. Study done at Guwahati among medical and nursing students majority had good knowledge about hand hygiene and there was no statistically significant difference between them regarding knowledge [15]. Saudi Arabian students had inadequate knowledge about hand hygiene and the study recommended need of structured curriculum to improve their knowledge [16]. Among the under-graduate medical students from Mumbai only $12.2 \%$ had good level of hand hygiene knowledge [17]. Even among the students at Albaha the knowledge about hand hygiene was inadequate [18]. 


\section{Conclusion}

The knowledge about hand hygiene was not satisfactory among the students. Formal training was received by some students only. Hand hygiene is very important for prevention of infections from the healthcare personnel to the patients and vice versa. Hand hygiene training can be made mandatory for medical, dental and nursing students as they handle patients. Hand hygiene can also be included in the curriculum so that its importance is emphasized on the students.

Impact of the current study: The current study has added to the available evidence that knowledge about hand hygiene is not satisfactory among the medical, dental and nursing students who are health care professionals responsible for spreading infections to the patients. This evidence can be used in designing curriculums to include hand hygiene and make it mandatory so that the students practice it and will help in reducing infections.

\section{Contribution of Authors}

- Chaitali Gore: Involved in designing the study, data analysis, manuscript writing and review

- Bindu M: Involved in designing the study, data collection, data analysis, manuscript writing

- Lubdha Saxena: Involved in designing the study, data collection, data analysis, manuscript writing

\section{Acknowledgments}

Authors would like to thank the management of Vydehi Institute of Medical Science and Research Centre for all the facilities provided for this study. We would also like to thank Preethi G, Srujana. A and Dhanya Rafi for their help in conducting the study.

\section{Reference}

01. World Health Organization. WHO Guidelines on Hand Hygiene in Health Care- First Global Patient Safety Challenge Clean Care Is Safer Care. Geneva- World Health Organization. 2009. Available at: [Article] [Crossref]

02. Hand hygiene- Why, How and When.

Available at: [Article] [Crossref]
03. Allegranzi B, Nejad SB, Combescure C, et al. Burden of endemic health-care-associated infection in developing countries- systematic review and meta-analysis. The Lancet. 2011;377(9761)228-241.

doi: $\quad 10.1016 / \mathrm{s} 0140-6736(10) 61458-4 \quad$ [Crossref]

04. Methai E, Allegranzi B, Kilpatrick C, Pittet D. Prevention and control of health care associated infection through improved hand hygiene. Indian J Med Microbiology. 2010;28(2)100-6.

[Crossref]

05. Rumbana R, Yu C, Pena A. A point-in-time observational study of hand hygiene practices of health care workers in Intensive Care Unit of St Luke's Medical Center. Phil J Microbiol Infect Dis. 2001;30;3-7.

[Crossref]

06. Creeddon SA. Hand hygiene compliance exploring variations in practice between hospital. Nurse Times. 2008 Dec;104(49)32-5.

[Crossref]

07. Trick WE, Vernon MO, Hayes RA, Nathan C, Rice TW, Peterson $B J$ et al. Impact of ring wearing on hand contamination and comparison of hygiene agents in a hospital. Clin Infect Dis. 2003 Jun;36(11)1383-90.

[Crossref]

08. Nabavi M, Alavi-Moghaddam M, Gachkar L, Moeinian M. Knowledge, attitudes, and practices study on hand hygiene among Imam Hossein Hospital's residents in 2013. Iranian Red Crescent Medical Journal. 2015;17(10). doi: $\quad 10.5812 /$ ircmj.19606.e19606 [Crossref]

09. AmissahI, Salia S, Craymah J. A Study to Assess Hand Hygiene Knowledge and Practices among Health Care Workers in a Teaching Hospital in Ghana. International Journal of Science and Research (IJSR). 2016 Aug;5(8)301-7. [Crossref]

10. Thakker VS, Jadhav PR. Knowledge of hand hygiene in undergraduate medical, dental and nursing students- A cross-sectional survey. J Family Med Prim Care. 2015;4;582-6.

[Crossref] 
11. Maheshwari V, Kaore NC, Ramnani VK, Gupta SK, Borle A, Kaushal R, et al. A study to assess knowledge and attitude regarding hand hygiene amongst residents and nursing staff in a tertiary health care setting of bhopal city. J Clin Diagn Res. 2014;8;DC04-7.

[Crossref]

12. Kamble VS, Biradar SM, Takpere A, Reddy S. Knowledge of hand hygiene practices among students of ESIC medical college, Gulbarga, Karnataka, India. Int J Community Med Public Health. 2016;3;94-8.

[Crossref]

13. Nair SS, Hanumantappa R, Hiremath SG, Siraj MA, Raghunath P. Knowledge, Attitude, and Practice of hand hygiene among medical and nursing students at a tertiary health care centre in Raichur, India. ISRN Preventive Medicine. 2014;2014;4.

doi: $10.1155 / 2014 / 608927.608927 \quad$ [Crossref]

14. Sultana $M$, Mahumud RA, Sarker AR, Hossain SM. Hand hygiene knowledge and practice among university students- evidence from Private Universities of Bangladesh. Risk Management and Healthcare Policy. 2016;9;1320.

doi: 10.2147/rmhp.s98311 [Crossref]
15. Goswami K, Baruah R. Study to Assess Knowledge, Attitude and Practice of hand hygiene among Medical and Nursing Students at Guwahati Medical College \& Hospital, Guwahati, Assam. Indian J of Basic and Applied Medical Research. 2016 Mar;5(2)322-28.

[Crossref]

16. Hamadah R, Kharraz R, Alshanqity A, AlFawaz $D$, Eshaq AM, Abu-Zaid A, et al. Hand hygieneKnowledge and attitudes of fourth-year clerkship medical students at alfaisal university, college of medicine, riyadh, Saudi Arabia. Cureus. 2015;7;e310. [Crossref]

17. Modi P D, Kumar P, Solanki R, et al. (July 12, 2017) Hand Hygiene Practices Among Indian Medical Undergraduates- A Questionnaire-Based Survey. Cureus. 9(7)e1463.

doi: $10.7759 /$ cureus.1463 [Crossref]

18. Bingawi1 $\mathrm{H}$, Alghamdi $\mathrm{N}$, AlghamdiS, Alghamdi M, Alghamdi N, Alzahrani A et al. Hand hygiene Perception and Knowledge of Albaha University Medical Students, 2016. IOSR Journal of Pharmacy. 2017 Jan;7(1)37-45.

[Crossref] 